\title{
A TEMPORAL AND SPATIAL ANALYSIS OF URBAN HEAT ISLAND IN BASIN CITY UTILIZING REMOTE SENSING TECHNIQUES
}

\author{
Hsiao-Tung Chang ${ }^{a *}$ \\ ${ }^{a}$ Professor, Department of Architecture and Urban Design, Chinese Culture University. 55 Hua-kang Road, Yang Ming Shan, 111 \\ Taipei, Taiwan -changht4613@gmail.com
}

Commission VI, WG II/3

KEY WORDS: Basin City; Urban Heat Island; Spatial-Temporal Analysis; Remote Sensing; Landsat Satellite Imagery.

\begin{abstract}
:
Urban Heat Island (UHI) has been becoming a key factor in deteriorating the urban ecological environment. Spatial-temporal analysis on its prototype of basin city's UHI and quantitatively evaluating effect from rapid urbanization will provide theoretical foundation for relieving UHI effect. Based on Landsat 8, ETM+ and TM images of Taipei basin areas from 1900 to 2015, this article has retrieved the land surface temperature (LST) at summer solstice of each year, and then analysed spatial-temporal pattern and evolution characters of UHI in Taipei basin in this decade. The results showed that the expansion built district, UHI area constantly expanded from centre city to the suburb areas. The prototype of UHI in Taipei basin that showed in addition to higher temperatures in the centre city also were relatively high temperatures gathered boundaries surrounded by foot of mountains side. It calls "sinking heat island". From 1900 to 2000, the higher UHI areas were different land use type change had obvious difference by public infrastructure works. And then, in next 15 years till 2015, building density of urban area has been increasing gradually. It has the trend that UHI flooding raises follow urban land use density. Hot spot of UHI in Taipei basin also has the same characteristics. The results suggest that anthropogenic heat release probably plays a significant role in the UHI effect, and must be considered in urban planning adaptation strategies.
\end{abstract}

\section{INTRODUCTION}

\subsection{General Introduction}

The temperature in London was found that warmer than its surrounding rural areas, it difference usually larger at night than during the day when winds are weak. This is the theme most frequently discussed in the literature since its discovery by Luke Howard (1818). Since then, it opened the world's attention on the microclimate temperature changes. Till 1958, Gordon Manley was the one who named "urban heat island; UHI) to describe the phenomenon was published in the Quarterly Journal of the Royal Meteorological Society (Manley, 1958). UHI no uniform definition, refers to: the effect describes the influence of urban surfaces on temperature patterns in urban areas as opposed to surrounding areas (Oke, 1982).

The UHI occurs as a result of a combination of anthropogenic heat discharge, decreased vegetation cover, and increased use of artificial impervious surface materials such as concrete and asphalt (Amiri et al. 2009). The UHI is caused by the storage of solar energy in the urban fabric during the day and release of this energy into the atmosphere at night. The process of urbanization and development alters the balance between the energy from the sun used for raising the air temperature (heating process) and that used for evaporation (cooling process), because the cooling effect of vegetated surfaces is replaced by impervious engineered surfaces. Many factors influence urban heat island intensity, including local and synoptic weather, season, time of day, size of the city and its geographical location, urban morphology, and anthropogenic heat. Oke (1973) and Park (1986) demonstrated that the UHI intensity increases as the urban population increases, and they provided functional relations associating UHI intensity with population. It is well known that the UHI intensity is strong on clear and windless nights and exhibits diurnal and seasonal variations (Kim and Baik 2002).

\subsection{The pattern of sinking heat island on basin-city}

Most of Existing researches discussed the UHI temperature distribution patterns which were roughly based on plain terrain urban intensity of land use as a reference. The temperature of the heat island presents bell hammer and concentric distribution, where lower temperature in suburbs, and increasingly becoming the centre of the temperature to go along with the highest density of land use. However, this UHI type is exceedingly difficult to explain heat island temperature distribution patterns of basin-city. Ascend thermal airflow on basin city enveloped by the foul air to lead hot air sinking along with the mountain in the basin edge barrier, thereby affecting UHI temperature rise than adjacent suburbs on basin edge. We called "sinking heat island". Few papers could topography-depicted heat island of basin-city, also failed to prove theoretical hypothesis.

While it reviewed UHI on basin city, some papers mentioned, but focused on albedo increase (Taha, 1997), pavements and rooftops with reflective surfaces (Akbari et al.,2003), average precipitation decrease (Ochoa, 2015), Humidity and anticyclone conditions of the UHI (Kassomenos, 2006) etc.

\subsection{Spatial-Temporal Analysis by remote sensing}

Traditionally, urban temperatures have been measured in terms of near-surface air temperature (screen-level) using terrestrial weather station networks and quantified using the urban heat island intensity (UHII) metric (Oke 1987; Kim and Baik 2002; Di Sabatino et al. 2009), which is the maximum difference between urban and background rural temperatures for a given point in time (Oke 1987; Kim and Baik 2002; Kolokotroni and

* Corresponding author 
Giridharan 2008). The first remote sensing observation was reported by Rao (1972). Since then, a variety of satellite-based combinations have been used to make remote observations of UHI, or of urban surface temperatures over a range of scales (e.g. Balling and Brazel 1987; Roth et al., 1989). Studies that have investigated the spatial pattern of UHIs have employed data from a range of satellite sensors, medium spatial resolution thermal images provided by the Landsat Thematic Mapper (TM) and ASTER instruments allow a detailed analysis of the relationship between urban environments and surface temperatures (Voogt and Oke 2003).

\subsection{The approach in this analysis}

Taipei city is situated at the centre of the Taipei basin in northern Taiwan. The Taipei basin belongs to the administrative systems of Taipei and New Taipei City, forming an urban living circle of twin cities. Developments of the twin cities are inseparable, especially with the extension and development of traffic networks, such as the MRT. The lives of residents have long broken down any administrative boundaries to form a greater Taipei living circle. Rapid urbanization of land use is the main problem of Taipei basin. Since the late 1980s, real estate developers' eager to cash in on a booming housing market have managed and proceed with large housing projects in the foothills. The urban developing was taken into consideration by urban planners and resulted in over-development along the Keelung River, main cross over Taipei basin. Considering the inhabitants and citizens lives and properties safety, the government finally began the Keelung River Straighten Reconstruction and finished the whole reconstruction in 1996. After the 1990s, underground railway, Taipei MRT network, and other transportation construction to be completed in nearly pass two decades to relieve traffic pressure, therefore the high-tech intensive urban development and third stage for service-based industry gradually replacing the factory buildings began to main development approach.

In this high-speed growing basin city, the temporal change of the UHI and spatial distribution of geographical features, in particular, to attract our attention. This study takes remote sensing techniques to analysis spatial-temporal issues, the purpose are : (1) to analyse the spatial distribution patterns of the Taipei basin heat island effect; (2) to research the Taipei basin heat island affect in the long-term changes; (3) temporal and spatial analysis of hot spots of Taipei basin.

\section{STUDY AREA, DATA, AND METHODS}

\subsection{The scope of the study}

Taiwan is an island located in the Western Pacific Ocean in East Asia, with a total area of $36,000 \mathrm{~km}^{2}$ (Figs. 1). The population is approximately 23 million. The climate is subtropical, with very hot weather concentrated into the summer months (June, July and August). The Taipei Basin, located at the northern tip of Taiwan, is he capital to Taipei City, which, together with the surrounding New Taipei City, comprises Taiwan's largest metropolitan area. An estimated 6.5 million people live in the Taipei region. The elevations of Taipei basin plains are between 0-40 meters, and the sounding mountain from a height 500 to 1000 meters. Gently sloping from the northwest to the southeast, which is shaped like an inverted triangle at the apex of Guandu, Sanxia, and Nankang. The length from east to west width is 17 kilometers, and 24 kilometres north-south sides. Nearly triangular in shape, the Basin is bordered with the Western Foothills to the south and east, the Tatun volcanoes to the north, and the Linkou Tableland to the west. It is occupied by the floodplain of the Danshui River, which has been developed into the largest and foremost important metropolis of Taiwan. The river basin has three main tributaries: the Dahan, Sindian and Keelung rivers.

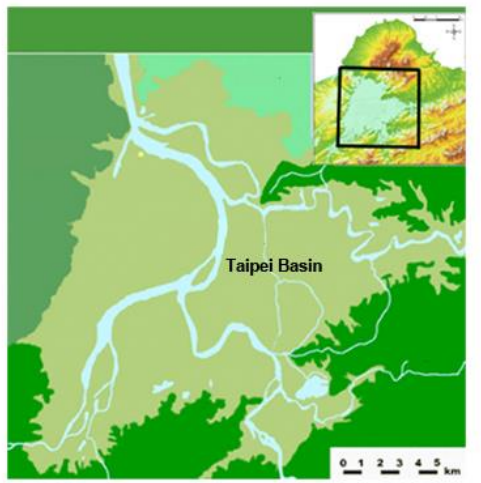

Figure 1. Taipei basin of Taiwan

\subsection{Satellite image data}

In the field measurement approach, the pattern of near surface temperature in urban area is generally compared with that in rural area. This involves the analysis of statistics of urban-rural differences based on fixed, mobile or grouped monitoring stations. One should note the limitations of the field measurement, such as time-consuming method, the incapability of achieving an overall picture of UHI, and difficulties in reaching consistent results. In addition, with the advancement of sensor technology constructed in satellites, remote thermal observation of UHI becomes possible. To solve a micro-scale problem and to obtain required information at the same time are available in nowadays. Taipei basins are analysed for the study of the surface temperature from the $\mathrm{ETM}^{+}$image data. Although the thermal spectrum of thermal sensors is composited by pixel size of $60 \mathrm{~m} * 60 \mathrm{~m}$ of the Landsat $\mathrm{ETM}^{+}$, a method originally devised for emissivity correction in the conversion of thermal image data to surface temperature has the effect of decreasing the pixel size through image fusion, resulting in both spectral and spatial improvements. We use three major image data of midsummer, one is from Landsat TM5 image on 22 June 1990, Landsat ETM+7 on 21 June 2000, and the other one is from Landsat 8 on 22 June 2015.

\subsection{Methods}

2.3.1 Normalization difference vegetation index , NDVI: The normalized difference vegetation index (NDVI) is a simple graphical indicator that can be used to analyse remote sensing measurements, typically from satellite image data, and assess whether the target being observed contains live green vegetation or not. Consequently, we also explored a transformation of NDVI into values associated with cover fraction using empirical relations with vegetation indices, as a possible basis function. Normalized Difference Vegetation Index (NDVI), given by:

$$
N D V I=\frac{B_{\text {nir }} B_{\text {red }}}{B_{\text {nir }}+B_{\text {red }}}
$$

Where nir and red are the at-surface reflectivity obtained from sensor bands located in the near infrared (nir) and red spectral regions. This spectral reflectance are ratios of the reflected over the incoming radiation in each spectral band individually, hence they take on values between 0.0 and 1.0. By design, the NDVI itself thus varies between -1.0 and +1.0 . It can be seen from its mathematical definition that the NDVI of an area containing a 
dense vegetation canopy will tend to positive values (almost from 0.3 to 0.8 ). Then, shrub and grassland that generally exhibit a near-infrared spectral reflectance somewhat larger than the red, and thus tend to also generate rather small positive NDVI values (assume 0.1 to 0.2 ). Lastly, low, negative values represent built area (approximately 0 to -0.4 ); the other lower values than -0.5 indicate lake and rivers.

2.3.2 Land surface temperature from thermal band of TM/ETM+ and TIRS: The main information source of urban heat environment from satellite Landsat, and the thermal infrared spectrum is the 6 th wave band $(10.4 \sim 12.5 \mu \mathrm{m})$. Landsat TM5 and ETM+7 in different timing are similar for the study of urban thermal environment. Thermal remote sensor can detect the radiation emission from objects on land surface, which is counted in pixel unit as average temperature.

The algorithm of deriving brightness temperature from Landsat TM/ETM+ images was proposed in two steps [7]. First, the radiation luminance is computed form the digital numbers (DNs) of band 6 by the equation:

$$
L_{\lambda}=\operatorname{Gain}_{\lambda} D N_{\lambda}+\operatorname{Bias}_{\lambda}
$$

Where $L_{\lambda}$ represent the radiation luminance $\left(\mathrm{mw} \cdot \mathrm{cm}^{-2} \cdot \mathrm{sr}^{-1} \mu \mathrm{m}\right.$ 1) , Gain TM/ETM+ is $0.005361, \mathrm{DN}$ are the 6-band image grey values from 0 to 255 , Bias is a constant equal to 0.124 . While in Landsat 8 , its gain value is $3.342 \times 10^{-4}$ and offset value equal to 0.1 . Then, it calculates the brightness temperature $\left(T_{k}\right)$ using the Planck function.

$$
T_{k}=\frac{k_{1}}{\ln \left(\frac{K_{2}}{L}+1\right)}
$$

Where, $\mathrm{K}_{1}$ and $\mathrm{K}_{2}$ are the prelaunch calibration constants, and $\mathrm{b}$ describes effective spectral range. For Landsat TM images, $\mathrm{K}_{1}=1282.7108$ (Kelvin), $\mathrm{K}_{2}=666.039\left(\mathrm{wm}^{-2} \mathrm{sr}^{-1} \mu \mathrm{m}^{-1}\right)$. In Landsat 8 , there are two bands of TIRS one is band 10 which $\mathrm{K}_{1}=1321.08$ (Kelvin), $\mathrm{K}_{2}=774.89\left(\mathrm{wm}^{-2} \mathrm{sr}^{-1} \mu \mathrm{m}^{-1}\right)$, and $\mathrm{K}_{1}=1201.14$ (Kelvin) $\mathrm{K}_{2}=480.89\left(\mathrm{wm}^{-2} \mathrm{sr}^{-1} \mu \mathrm{m}^{-1}\right)$ for band 11. The Kelvin temperature values obtained above are referenced to a black body. Therefore, corrections for spectral emissivity $(\varepsilon)$ became necessary according to the nature of land cover. Land surface temperature (LST) corrected with the emissivity was obtained from the equation. Formula (3) retrieval converted to:

$$
T_{s}=\frac{T_{k}}{1+\left(\frac{T_{k}}{h c /}\right) \ln }
$$

where $T s$ is surface temperature in Kelvin $(\mathrm{K}), \lambda=$ wavelength of emitted radiance (forTM/ETM+ which the 6th band wavelengths $[\lambda=11.5 \mu \mathrm{m}]$ was used, for TIRS that $10^{\text {th }}$ and $11^{\text {th }}$ band wavelengths are $[\lambda=10.3 \mu \mathrm{m}, 11.5 \mu \mathrm{m}]), \mathrm{h} * \mathrm{c} / \sigma\left(1.438 * 10^{-2}\right.$ $\mathrm{m} \cdot \mathrm{K})$, here $\sigma$ is Boltzmann constant $\left(1.38 * 10^{-23} \mathrm{~J} \mathrm{~K}^{-1}\right)$, $\mathrm{h}$ is Planck's constant $\left(6.626 * 10^{-34} \mathrm{~J} \cdot \mathrm{s}\right)$, and $\mathrm{c}=$ velocity of light $\left(2.998 * 10^{8} \mathrm{~m} \mathrm{~s}^{-1}\right)$.

The emissivity of water body $(\varepsilon \lambda)$ was estimated as 0.995 , and natural surface $\varepsilon_{\mathrm{n}}$ and build-up $\varepsilon_{\mathrm{b}}$ land (Griend, 1993; Masuda, 1988; Snyder, 1998). They were obtained using the following equation:

$$
\begin{aligned}
& \varepsilon_{\lambda}=1.0094+0.047 \ln (N D V I) \\
& \varepsilon_{\lambda}=1.0094+0.047 \ln (N D V I)
\end{aligned}
$$

where $\mathrm{Pv}$, is the vegetative proportion obtained according to Carlson \& Ripley (1997) as:

$$
P_{v}=\left[\left(N D V I-N D V I_{\min }\right) /\left(N D V I_{\max }-N D V I_{\min }\right)\right]^{2} \ldots(7)
$$

Here, NDVI $I_{\max }$ and $\mathrm{NDVI}_{\min }$ donated the values for dense vegetation and built-up areas. Describes the calculated mode of $T_{c}=T_{s}+273.15$ that converts temperatures measured in Kelvin temperature values to Celsius. $T_{c}$ is a given pixel of land surface temperature $\left({ }^{\circ} \mathrm{C}\right)$.

2.3.3 Analysis of UHI temperature: Due to the rapid urban climate change, it is difficult to compare the surface temperatures at different dates. Zhao et al. (2010) proposed UHI intensity instead of UHI temperature, which is defined as the maximum difference between urban LST and terrestrial average LST including rural and urban areas, as in equation:

$$
U H I_{I}=\operatorname{Max}\left(T_{c i}-T_{a}\right)
$$

where UHI is urban heat island intensity $\left({ }^{\circ} \mathrm{C}\right), \mathrm{T}_{\mathrm{ci}}$ is the LST of the ith pixel in the urban area $\left({ }^{\circ} \mathrm{C}\right), \mathrm{T}_{\mathrm{a}}$ is average LST of the whole terrestrial part of Taipei basin $\left({ }^{\circ} \mathrm{C}\right)$.

\section{RESULTS}

\subsection{Validation of air temperature}

Using the above methods and data, it calculated the land surface temperature data from 1990 to 2015 in Taipei basin. Figure 2 presents the variation of the analysis results of Landsat 8 with respect to the observed air temperature from weather station. In terms of two test methods which are normal probability plot are presented. The regression $\mathrm{R}^{2}=66.8 \%$ between observed air temperature and estimated air temperature, and its $\mathrm{F}$ value $=$ $61.49, \mathrm{P}$ value $<0.000$ of regression formula. As the normal probability plot demonstrates, most of the samples were distributed around the 1:1 line; thus, the estimation accuracy is relatively high.

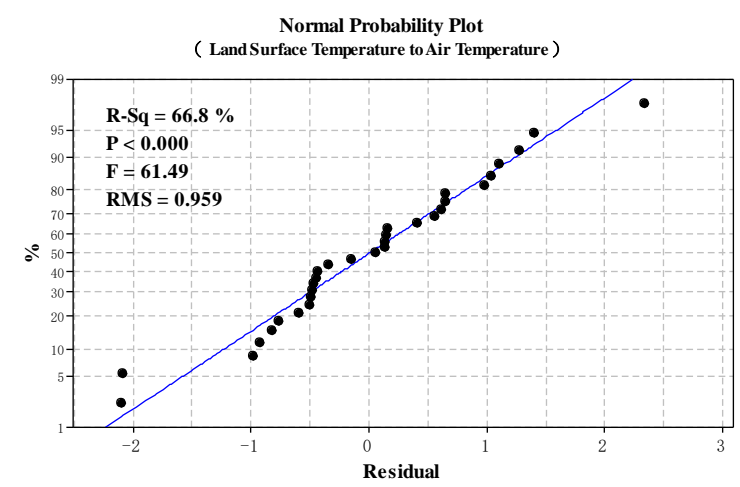

Figure 2. Normal probability plot between observed air temperature and estimated air temperature.

\subsection{Spatial distributions of air temperature}

3.2.1 The temperature and the UHI of 1990 in Taipei basin: Figure 3 presents the calculated spatial distribution of the air temperature in Taipei basin, 22 June, 1990. After checking the temperature of each hourly weather stations of Taipei metropolitan area, the study analysed the resulting temperature data error minimum appropriate resolution.

The figure also demonstrates that the temperatures in Taipei city changed mainly between $22^{\circ} \mathrm{C}$ and $34^{\circ} \mathrm{C}$, with an average of $24.89^{\circ} \mathrm{C}$. There were significant spatial differences in the temperature; the temperatures around the Tamsui river were developed districts typically higher than $30^{\circ} \mathrm{C}$, and the temperature typically exceeded $28^{\circ} \mathrm{C}$ in the urban areas. The low temperature in the surrounding mountains can be attributed to the transpiration and canopy shading effect of the covered forest, and the higher elevation. 
On the northwest to southwest the foot of Guanyin mountain, air temperature in urban areas was typically above $31^{\circ} \mathrm{C}$, which was significantly higher than the surrounding undeveloped areas, reflecting a significant UHI effect. This feature changes UHI effect, the reason is the east monsoon rising hot air basin topography enveloped by the foul air to produce hot air sinking by mountain terrain blocking, when the heat flow to the edge of the basin. Thereby affecting the edge of the basin caused higher UHI than suburb. The high UHI zone was centred at the main urban area and sprawled outwards towards the suburbs. The scope and intensity of UHIs were higher in the southern part than in the northern part of the main urban area apart from Xindian river.

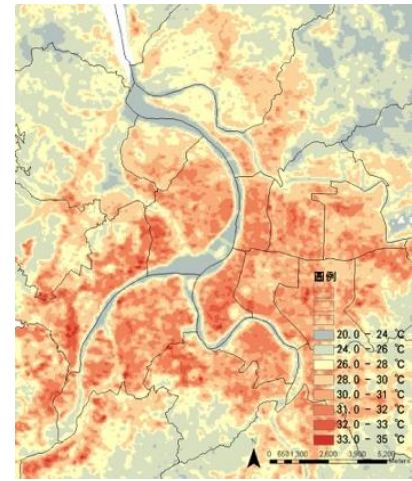

Air temperature in Taipei basin, 1990

Figure 3. Air temperature and UHI in Taipei basin, 1990.

3.2.2 The temperature and the UHI of 2000 in Taipei basin: Figure 4 shows the temperature of Taipei basin, 21 June, 2000. That also demonstrates that the temperatures in Taipei city changed highly to $38.1^{\circ} \mathrm{C}$, with an average of $27.32^{\circ} \mathrm{C}$. The high UHI zone was centred at the main urban area. The significantly areas changed of UHI effect were short cut areas of the Keelung river and Xinyi District, due to urban developed from water or suburbs to height density districts.
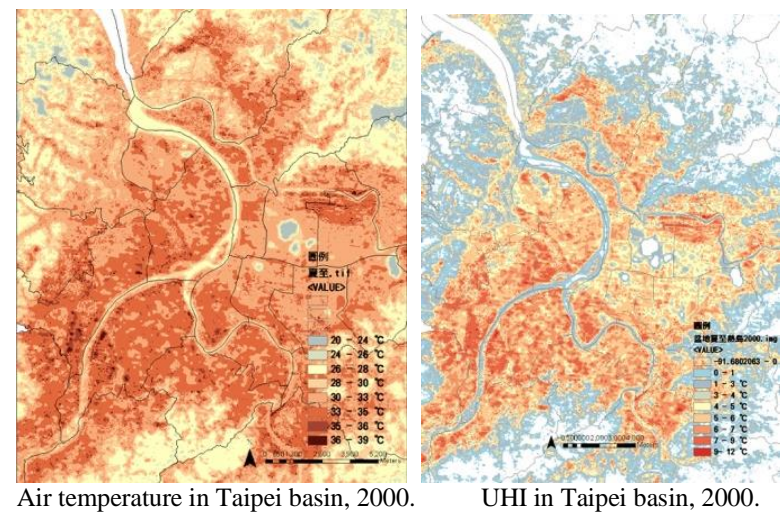

Air temperature in Taipei basin, $2000 . \quad$ UHI in Taipei basin, 2000.
Figure 4. Air temperature and UHI in Taipei basin, 2000.

3.2.3 The temperature and the UHI of 2015 in Taipei basin: The calculated air temperature in Taipei basin, 22 June, 2015 (show as Figure 5). The figure demonstrates that the temperatures in Taipei city changed mainly between $20^{\circ} \mathrm{C}$ and $36.1^{\circ} \mathrm{C}$, with an average of $23.7^{\circ} \mathrm{C}$. There were significant spatial differences in the west sites of the Tamsui river typically higher than $32^{\circ} \mathrm{C}$, and the UHI temperature typically exceeded $6^{\circ} \mathrm{C}$. Another high UHI zone was centred at the eastern of main urban area in Taipei city.



Air temperature in Taipei basin, 2015

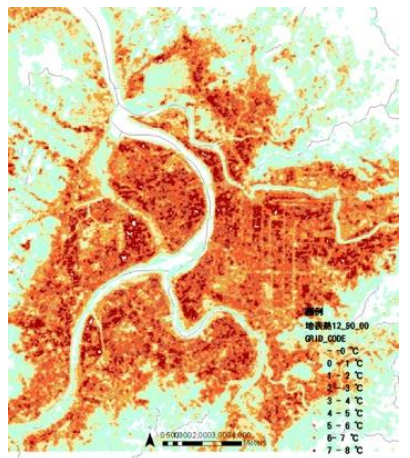

UHI in Taipei basin, 2015.

Figure 5. Air temperature and UHI in Taipei basin, 2015.

\section{DISCUSSION}

\subsection{Characteristics of Urban Heat Island Effect for basin terrain}

For the cities featured as plain terrain, the distribution of heat island temperature is in the form of bell. The temperature is lower in suburb and then gradually increases when going closer to the city centre, peaking at the population-density area or the maximized use of the land. The temperature subsequently drops down by going far away the city centre, minimizing at the suburbs (Xiande Lin, 2001). The variation characteristics of Urban Heat Island, however, displays special distribution morphology when comes to the basin topography. The belt of heat island effect emerges with higher temperature for the suburbs along the edges of the mountain. The difference between this phenomenon and description in the reference is greatly large. It's deducted from the study that the upward thermal current is enveloped by the foul air, generating the sinking thermal current, which is obstructed by the mountain barrier when it is blew to the edge of the basin terrain by the wind in summer. The suburbs along the edge of the basin terrain are therefore affected, increasing the temperature of the heat island. It called "sinking heat island". From Figure 6, it's obviously showed that the temperature of heat island is relatively higher from Linkou Plateau, Mt Mountains to the edge of Peitou Mountains, constituting the belt of heat island caused by sinking thermal current. The similarities also lay in the effect of heat island between the edge areas of north-eastern and south-eastern mountains, embodying clear aggregation boundaries of high temperature.
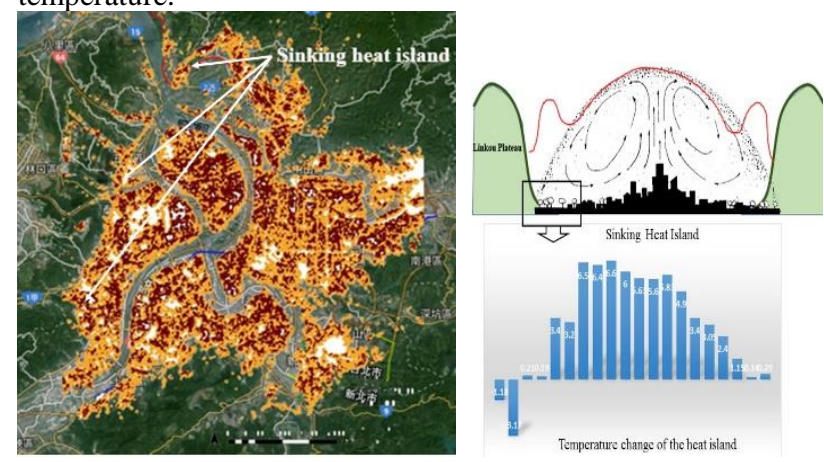

Figure 6. The sinking heat island in Taipei basin, 2015. 4.2 Analysis of heat effect with spatial-temporal changes

Figure 7 reflects the difference of heat island temperature between 2000 and 1990. The counterpart for 2015 and 2000 is concluded in Figure 8. 


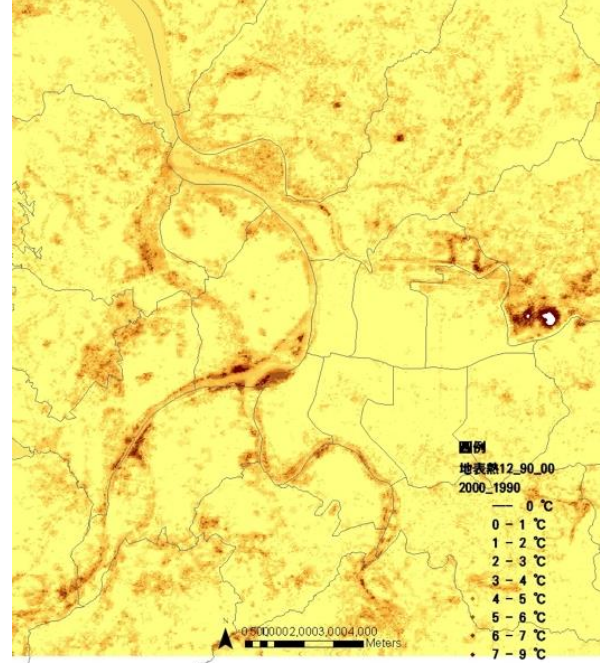

Figure 7. difference of heat island temperature between 2000 and 1990

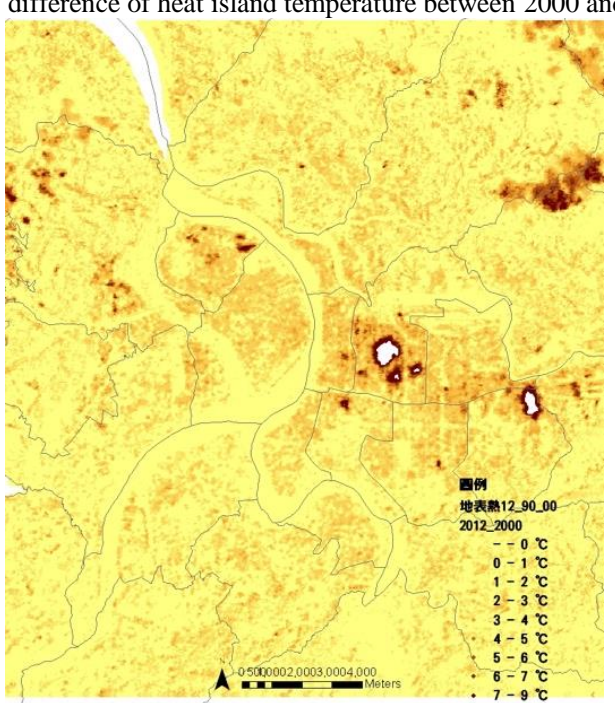

Figure 8. difference of heat island temperature between 2015 and 2000

According to Eludoyin et al. (2014), the population and social economic activities affects the spatial distribution of the cities, which is also revealed from the characteristics of the temporal and spatial changes. The temperature of heat island is increased due to the artificial development from 1990 to 2000. Such as interception of winding river course and selection of straightened river course for Keelung River, south-to-north trestle along the Fresh-water River and development of double flooding mitigation roads in New Taipei City. The temperature along the fresh-water river tends to ascend up from 1990-2000 from both Figure 6 and 7. But, the temperature of this area tends to decline from 2000-2015.

The spatial distribution of UHI is in accordance with the extension direction of city built area. From 2000 to 2015, the intensity of UHI is aggravated following the city development. The temperature of the city area in 2015 is obviously higher than that in 2000. And the temperature of the surrounding suburbs and forestry and mountains are in average. The increase of the surrounding temperature also is in positive as the urbanization affects with population concentration. The heat island areas to the western side of Fresh-water River tend to concentrate to the cities, among which Luzhou, Sanchong, Xinzhuang, Wugu and Banqiao are increase in temperature. The thermal current is accumulated at the foot of Mt Mountains to further increase the temperature, resulting from the wind in summer which is mainly from the north, east and partially southwest. On the other side, many citizens are forced to move to Luzhou, Sanchong, Xinzhuang and Banqiao, etc. under the pressure of high price of houses in city areas in Taipei City, causing the temperature rise of heat island with population concentration.

\subsection{Hotspot analysis of temporal and spatial changes}

The area which exceeds $6{ }^{\circ} \mathrm{C}$ in temperature of heat island is shown in the colour of khaki from 1990 to 2000. And the counterpart is shown in the colour of brown from 2000 to 2015 (see Figure 8). The locations in Figures are the hot spots for each year, when city development or artificial construction is intensive with obvious surge of UHI temperature.

UHI in Seoul departs from the locations and topography of main commercial and industrial departments, embodying the concentric structure of heat island. The areas near the northern and southern mountains are colder (Kim, 2002). The UHI effect of the basin terrain in Taipei is obviously affected by the topography of terrain without uniform concentric pattern of dispersion. The hotspots of heat island increasing preliminarily focus on interception of winding river course and selection of straightened river course for Keelung River, south-to-north trestle along the Tamsui River, Shezi island, Shilin, development of double flooding mitigation roads and Xinzhuang sub-centre. The major construction traces of the government are reflected on the city hotspots.

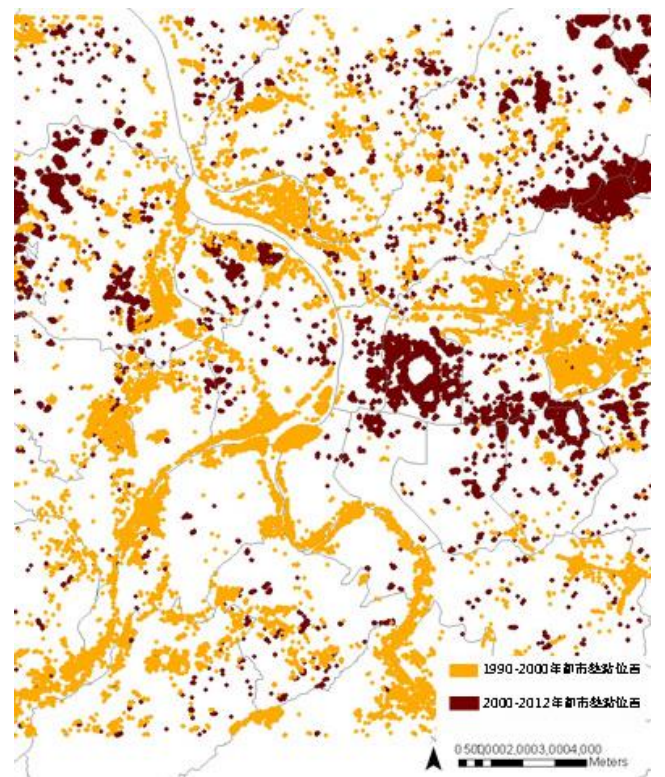

Figure 9 hot spot locations from 1990 to 2015

The hotspots in later period emerge at the central areas of the basin terrain of Taipei City, ranging from Nangang, Songshan, and Datong of Taipei City to Sanchong and Luzhou of Xin Taipei City, etc. The spread of city built areas are deepened by the spatial distribution and extension of UHI. The temperature tends to increase for the development of Taipei City and surrounding areas from 1990 to 2000. The surface hotspots with high temperature gradually extend outside, from spatial distribution, and moves to suburbs until 2015.

\section{CONCLUSIONS}

UHI effect is influenced by the city expansion and thermal discharge from high-rise buildings and man. UHI refers to the phenomenon that the temperature of partial city areas is higher than that of the surrounding suburbs due to the change of long wave radiation outward, which arises from the heat discharge 
from the population-condensed areas, change of ground evapotranspiration characteristics and the block of high-rise buildings. In this paper, the development and evolution of heat island effect for basin terrain is interpreted in sight of the topographic characteristics. Data of satellite image from Landsat 5TM、Landsat 7ETM+ and Landsat 8 are applied to analysis the UHI temperature of Taipei City from 1990-2015 to further comprehend the overall influence of climate changes and the spatial variation of the city. The research achievement is shown as follows based on the calculation of Landsat surface heat, data correction and comprehensive comparison and the characteristics of heat island temperature of basin terrain of Taipei from the view of temporal and spatial changes.

(1) During 1990-2015, the temperature of Taipei centre gradually increases and UHI expands to the surrounding suburbs as time changes, such as Muzhan of Nangang in eastern part, Xindian in southern part and Wugu in western part, resulting in the effect of UHI.

(2) Sinking heat island: The morphology of heat island of Taipei basin terrain is affected by its topography of basin terrain. The upward thermal current is enveloped by the foul air, generating the sinking thermal current, which is obstructed by the mountain barrier when it is blew to the edge of the basin terrain, increasing the temperature of heat island for the edge area of terrain. The areas with clear higher temperature of heat island also include surrounding mountains, such as Linkou Plateau, Mt Mountain, edge of Peitou Mountain, the lake in north-eastern Taipei and the four beasts Mountain, showing the obvious concentration boundaries of high temperature.

(3) Artificial development and public engineering lead to the temperature increasing of heat island from 1990 to 2000, such as interception of winding river course and selection of straightened river course for Keelung River, south-to-north trestle along the Fresh-water River and development of double flooding mitigation roads in New Taipei City. From 2000 to 2015, the heat island is intensified following the areas of city development. The spatial distribution and extension of UHI is in accordance with the city built areas. The same feature can also be found to the hot spots with heat island increasing.

The greater the intensity of city land use is, the higher the temperature of UHI is. The population intensity should be controlled reasonably for the metropolis area with basin terrain, considering the city capacity. The Greenland system is planned in comprehensive way to achieve a suitable living environment and reduce city thermal environment through the regulation and deployment of multi-level land use.

\section{REFERENCES}

Akbari, H. 2003. Measured energy savings from the application of reflective roofs in 2 small non-residential buildings. Energy. 28:953-967.

Amiri, R., Q. Weng, A. Alimohammadi, and S. K. Alavipanah. 2009. The Spatial-Temporal Dynamics of Land Surface Temperatures in Relation to Fractional Vegetation Cover and Land Use/Cover in the Tabriz Urban Area, Iran. Remote Sensing of Environment. 113: 2606-2617.

Carlson, T. N., D. A. Ripley, 1997. On the relation between NDVI, fractional vegetation cover, and leaf area index. Remote Sensing Environment, 62. pp. 241-252.
Eludoyin, O.M., L.O. Adelekan, R. Webster and A.O. Eludoyin. 2014. Air temperature, relative humidity, climate regionalization and thermal comfort of Nigeria. International Journal of Climatology. 34(4). Pp.2000-2018.

Howard, Luke, 1818. The Climate of London Deduced from Metrological Observations, W. Phillips, London.

Kassomenos, P. A., Katsoulis, B. D., 2006. Mesoscale and macroscale aspects of the morning Urban Heat Island around Athens, Greece. Meteorology and Atmospheric Physics. 94(14), pp.209-218.

Kim, Y.H. and Baik, J.J., 2002. Maximum urban heat island intensity in Seoul. Journal of Applied Meteorology, 41: 651-59.

Kolokotroni, M., and R. Giridharan. 2008. Urban Heat Island Intensity in London: An Investigation of the Impact of Physical Characteristics on Changes in Outdoor Air Temperature during Summer. Solar Energy. 82, pp.986-98.

Lin, Xiande. 2001. Experimental Analyses on Urban Heat Island Effect and Its Improvement Strategies in Coastal Cities of Taiwan--Analyses for Tainan, Kaoshoung and Hsinchu. City and Planning. 28(3), pp.323-341.

Manley, Gordon. 1958. On the frequency of snowfall in metropolitan England, Quarterly Journal of the Royal Meteorological Society. 84, pp.70-72.

Ochoa, Carlos A., Quintanar, Arturo I., Raga, Graciela B., 2015. Changes in Intense Precipitation Events in Mexico City. Jounal of Hydrometorlogy. 16(4). pp.1804-1820.

Oke, T. R. 1982. The energetic basis of the urban heat-island. Quarterly Journal of the Royal Meteorological Society, 108(455), $1-24$.

Oke, T. R., 1973. City size and the urban heat island. Atmospheric Environment Pergamon Press, 7.pp.769-779.

Oke, T.R.,1987. Boundary Layer Climates, Methuen, USA.

Park, H.-S., 1986. Features of the heat island in Seoul and its surrounding cities. Atmospheric Environment. 20, 1859-1866.

Rao, P. K., 1972. Remote sensing of urban heat islands from an environmental satellite. Bulletin of the American Meteorological Society. 53. Pp.647 - 648.

Roth, M., T. R. Oke, and W. J. Emery. 1989. Satellite-Derived Urban Heat Islands from Three Coastal Cities and the Utilization of Such Data in Urban Climatology. International Journal of Remote Sensing. 10. Pp.1699-720.

Taha, Haider, 1997. Urban climates and heat islands: albedo, evportranspiration, and anthropogenic heat. Energy and Building, 25.pp.99-103.

Voogt, J. A., and T. R. Oke. 2003. Thermal Remote Sensing of Urban Climates. Remote Sensing of Environment. 86. Pp.37084.

Zhao, X. F., J. C. Huang, H. Ye, K. Wang, Q.Y. Qiu. 2010. Spatiotemporal changes of the urban heat island of a coastal city in the context of urbanisation, International Journal of Sustainable Development \& World Ecology. 17(4). pp.311- 316. 